\title{
PESANTREN, TAREKAT, DAN KEDAMAIAN
}

\author{
DUDUNG ABDURAHMAN
}

There are two main steps must be conducted when facing the social conficts, nomely mapping the factors causing the conflict and seeking its solution. One of the way to overcome the conflicts is understanding the potencies of peacefulness in pesantren as a religious institution with its specific subculture in this country. Dealing with the problem "peacefulness", the sufism based-pesantren, for example, tends to develop not only the root of peacefulness values between human being and God, but also enrich the spirituality needed by the modern society. The article will depict a model of potency development of peacefulness from the tarekat pesantren perspective. By taking case of pondok pesantren Suryalaya Tasikmalaya, the tarekat pesantren- with its educational systemtends to develop the peace-culture in their community and its environment.

\section{Pengantar}

Semenjak konflik sosial secara multidimensional bermunculan di Indonesia, telah banyak kajian dan hasil penelitian baik dalam upaya pemetaan faktor-faktor konflik itu maupun upaya pencarian resolusinya. ${ }^{1}$ Kini sudah saatnya upaya serupa diarahkan kepada pencarian potensi kedamaian yang mungkin dapat diimplementasikan dalam mengatasi berbagai konflik serta memperkuat bangunan kesatuan bangsa. Seperti halnya sumbersumber konflik ditemukan berasal dari berbagai faktor ideologi, sosial, ekonomi, politik, dan sebagainya,

'Upaya terakhir (pada September 2005) Lembaga Penelitian UIN Sunan Kalijaga telah melaksanakan diseminasi hasil penelitian unggulan mengenai Konflik Sosial dan Resolusinya di Indonesia. Hasilnya telah diterbitkan menjadi sebuah buku berjudul Fenomena Konflik Sosial di Indonesia: Dari Aceh Sampai Papua (2006). 
maka demikian pula sumber-sumber kedamaian dapat digali dari berbagai ajaran atau prinsip sesuatu gerakan sosial, orientasi kelembagaan, model kepemimpinan, dan lain-lain. Dalam hal ini misalnya potensi pesantren sebagai kelembagaan agama dan sub-kultur di negeri ini.

Kelembagaan pesantren dengan beragam corak pengembangannya dikenal dalam sejarah Islam di Jawa khususnya sebagai ujung tombak pendidikan dan pembinaan ajaran agama Islam. Bila ajaran agama ini seringkali dikategorikan secara umum menjadi tiga bidang, aqidah, syari'ab, dan tasawuf, maka corak pesantren antara lain teridentifikasi berdasar bidang-bidang tersebut. Terdapat pesantren yang secara khusus mengembangkan akidah seperti halnya Pesantren Miftahul Huda Manonjaya Tasikmalaya; Pesantren yang lebih konsen pada mengembangkan syariah/fiqh seperti Pesantren Situbondo Jawa Timur, dan banyak pesantren yang pengembangannya berbasiskan sufisme-tarekat seperti Pesantren
Suryalaya di Tasikmalaya; tetapi lebih banyak lagi pesantren yang orientasi pendidikannya merupakan kombinasi antara tiga aspek ajaran Islam itu.

Cukup menarik untuk dibahas dalam kaitannya dengan masalah "kedamaian" ini adalah pesantren yang berbasiskan pengajaran dan pengembangan sufisme-tarekat, karena bukan saja akar ajaran sufisme adalah untuk mencapai kedamaian antara manusia dengan Tuhan dan antar sesama manusia melainkan juga dalam fenomena terakhir ${ }^{2}$ mengenai keberdayaan sufisme-tarekat itu adalah sebagai salah satu alternatif pencarian kedamaian diri oleh mereka yang haus spiritual akibat kegersangan hidup materialistik dan dampak globalisasi. Demikian pula pemunculan gerakan tarekat-tarekat yang berpusat di pesantren-pesantren dengan implementasinya di bidang politik, sosial, dan keagamaan pada periode kontemporer hampir tidak dijumpai model-model gerakan mereka yang mengarah kepada radikalisme dan konflik, justru

${ }^{2}$ Dalam kasus tertentu, seperti misalnya pada masa Kolonial, sufisme-tarekat memang berpotensi juga dalam konflik, tetapi karena ideologi mereka pada saat itu dikembangkan dalam perlawanan terhadap penjajah yang "kafir'. Ternyata berbeda dengan perkembangan terakhir, khususnya berhadapan dengan penguasa pribumi, justru gerakan tarekat lebih akomodatif. 
beberapa gerakan tarekat bersikap akomodatif kepada penguasa maupun kepada gejala-gejala kehidupan yang dipandang sekuler.

Model potensi kedamaian dalam perspektif pesantren dan tarekat di sini ingin digambarkan secara garis besar, yaitu dilihat berdasar pola kepemimpinan pesantren, ajaran dan gerakan tarekat dalam kasus sejarah Pondok Pesantren Suryalaya. Kedamaian yang dimaksud pada tulisan ini dibatasi dalam kaitannya dengan kedamaian personal, sosial, dan politik.

\section{Kepemimpinan Pesantren dan Tarekat}

Dalam kepemimpinan pesantren di daerah Priangan khususnya, gelar gelar "kiyai" atau populer dengan sebutan "ajengan" biasa diberikan oleh masyarakat kepada seorang penggasuh pesantren, bahkan gelar itu merupakan sebutan masyarakat terhadap semua pemuka agama Islam. Gelar tersebut seringkali dibedakan berdasarkan status dan peranannya dengan "Ulama", karena ulama lebih dipahami sebagai para ahli pengetahuan Islam di kalangan kaum muslimin. Hiroko Horikoshi ${ }^{3}$ dalam studi tentang kyai dan ulama di pedesaan Jawa Barat melaporkan bahwa "kyai/ajengan" merupakan pemimpin kharismatik serta seorang ahli yang jauh lebih unggul daripada ulama. Ajengan berperan untuk membentengi umat terhadap kekuatan-kekuatan sekuler, sedangkan "ulama" adalah fungsoionaris agama dan bertanggungjawab dalam menjaga ortodoksi Islam. Perbedaan antara keduanya terletak pada derajat pengaruh yang dimiliki oleh jenis keahlian itu dan pengakuan ortodoksinya dari masyarakat. Penyebutan gelar ajengan atau kyai secara eksklusif lebih dominan dalam kultur masyarakat pesantren.

Gelar yang lebih eksklusif lagi adalah pemimpin tarekat. Meskipun kepemimpinan tarekat adalah paralel dengan sistem kepemimpinan pesantren, tetapi penyebutan gelarnya tidak sama. Pemimpin utama tarekat biasa disebut "khalifah". Gelar ini bukan pemberian masyarakat, tetapi diberikan oleh khalifah sebelumnya yang dikukuhkan melalui upacara hirqab (baiat). Seorang khalifah memiliki peran

${ }^{3}$ Baca, Hiroko Horikoshi, Kyai dan Perubahan Sosial, terj. Umar Basalim dan Andi Muarly Sunrawa (Jakarta : P3M, Cet. I, 1987), hlm. 1-3. 
sebagai guru mursyid (pembimbing), yang seringkali juga disebut sebagai syaikh. Dalam menjalankan kepemimpinannya, seorang khalifah dibantu oleh beberapa orang wakil (badal).

Profil pribadi pimpinan pesantren atau tarekat itu sangat menentukan kualitas gerakan dan aktivitas pesantren, sehingga "warna" pesantren adalah identik dengan pimpinannya. Seperti yang dialami dalam kepemimpinan awal Pesantren Suryalaya, Kyai Abdullah Mubarrok atau lebih populer dengan panggilan Ajengan Godebag kala itu tampil sebagai tokoh dominan pada kalangan elit agama di wilayah Priangan. Perjuangan dan dakwah tarekat Abdullah Mubarrok dikembangkan melalui ilmu tarekat yang bukan hanya zikrullah, sebagaimana inti ajaran Tarekat Qadiriyah wa Naqsyabandiyah, tetapi juga ilmu kesampurnaan, ilmu saepi, dan biji, yang semua ini merupakan ramuan dari zikrullah. + Pengembangan tarekat seperti itu memberikan daya tarik yang sangat kuat kepada penduduk, sehingga Ajengan Godebag sangat dihormati. Ia memperoleh dukungan serta keuntungan-keuntungan materi, sehingga ia dapat menambah sarana pesantren, seperti pembangunan madrasah untuk kegiatan pengajaran tarekat dan pembangunan pondok untuk para para pengikut yang datang dari daerah jauh. Sejak sekitar tahun 1934, di Suryalaya biasa diselenggarakan pengajian $m a$ naqiban pada setiap tanggal 11 Hijriyah, yang dihadiri para penganut dari berbagai cabangnya. ${ }^{5}$ Para pengikutnya datang berbondong-bondong ke sana dengan berbagai harapan, ada yang mencari ketenangan batin, meminta fatwa mursyid untuk mengatasi krisis kehidupan mereka, tetapi ada pula yang mengharapkan berkahnya untuk kesuksesan usaha atau kesaktian.

Prestise dan pengaruhnya bertambah besar setelah secara defenitif ia menduduki jabatan "khalifah" Tarekat Qadiriyah wa Naqsyabandiyah, meneruskan gurunya Kyai Tolkhah Cirebon, untuk wilayah Jawa Barat mulai tahun 1935. Kharisma Haji Abdullah Mubarrok di kemudian hari mendapatkan dukungan pula dari pejabat-pejabat

4Wawancara dengan K.H. Noor Anom, 8 Februari 1996.

${ }^{5}$ Besman,Sinar Hate, hlm. 12. 
pemerintah. Apalagi pada periode kemerdekaan Indonesia ia dikenal dekat dan mendukung pemerintahan Republik. Pada saat itu ia juga berperan membantu TNI semasa perang kemerdekaan maupun sewaktu terjadi pemberontakan DI/ TII. Pada usianya yang semakin tua, ia yang belakangan populer dengan panggilan "Abah Sepuh", lebih berperan sebagai pemberi fatwa atau nasihat kepada pemerintah maupun kepada para wakilnya. Kepemimpinan pesantren sepeninggalnya sejak 1956 dilanjutkan oleh puteranya, Ajengan Shohibul Wafa Tajul 'Arifin, yang akrab dipanggil "Abah Anom".6

Sikap dan kepribadian Abah Anom dalam menjalankan roda kepemimpinannya tercermin dari "motto hidup" yang selalu disampaikan sendiri atau dibacakan oleh wakilnya pada setiap pertemuan tarekat. Motto ini ditulis dalam bahasa Sunda sebagai berikut:

\section{RANGGEUYAN MUTIARA}

Ulah ngewa ka Ulama anu sajaman
Ulah nyalahkeun kana pangajaran batur

Ulah mariksa murid batur

Ulah medal sila upama kapanah

Kudu asih ka jalma anu mika ngewa ka maneh.?

\section{UNTAIAN MUTIARA}

Jangan benci pada ulama sejaman

Jangan menyalahkan pengajaran orang lain

Jangan memeriksa murid orang lain

Jangan berubah sikap meskipun disakiti orang

Harus menyayangi orang yang membenci kamu

Berdasar untaian mutiara ini dan juga beberapa karyanya yang lain, bahwa Abah Anom selalu bersikap toleran dan tidak antagonistik terhadap faham-faham keagamaan yang berbeda. Meskipun acapkali datang sorotan dari ulama sejaman, yang menganggap bahwa Abah Anom tengah menyebarkan ajaran

'Istilah "Abah" berasal dari kata Arab abun (ayah), di kalangan masyarakat Sunda Priangan ia merupakan panggilan akrab bagi orang tua yang dihomati, sedangkan sepuh (bahasa Sunda) berarti lebih tua dan tentu saja anonimnya adalah anom (yang muda).

${ }^{7}$ Dikutip dari Uqudul Juman, dalam Tanbih, hlm. 11. 
bid'ab dan sesat. ${ }^{8}$ Dia selalu bersikap santun kepada murid-muridnya dan hormat kepada para tamu yang datang dari segala lapisan masyarakat. Ceramah atau wejangan $\mathrm{Abah}$ Anom dirasa menyentuh lubuk hati para pendengarnya.

\section{Ajaran tarekat bagi Kedamaian}

Sebagaimana sufisme-tarekat pada umumnya, ajaran dan ritual yang dikembangkan Abah Sepuh maupun Abah Anom di Suryalaya tidaklah berbeda dengan yang dikembangkan oleh para pendahulu mereka ataupun oleh guruguru tarekat yang sama di tempattempat lain. Meskipun dalam hal tertentu Abah Anom telah berusaha memberikan keterangan atas ilmu tarekat Qadiriyah wa Naqsyabandiyah yang diinformasikan pencetusnya, Syeikh Ahmad Khatib Sambas.

Di dalam kitab Miftabus Sbudur, Abah Anom menyebutkan bahwa "tarekat itu pada hake- katnya adalah zikir", yakni pekerjaan yang sangat utama serta merupakan wasilab yang dapat menghubungkan manusia dengan Tuhannya. ${ }^{9}$ Zikir dimaksud ialah mengucapkan kalimat la ilaha illa Allab, atau kalimat nafi dan isbat, atau di kalangan umat Islam pada umumnya biasa disebut kalimab tayyibah atau kalimab taubid. Menurutnya, kalimat ini dapat membuka hati manusia dan membersihkan jiwa dari segala kotoran. Bagi orang yang senantiasa mengucapkan kalimat tersebut, akan memperoleh bermacam-macam kebaikan (karunia) Tuhan. ${ }^{10}$ Begitu agungnya kalimat tersebut, Abah Anom mengutip hadis Nabi yang diriwayatkan Ali bin abi Thalib:

Bahwa ia (Ali) pernah mendengar Rasullallah SAW. Menceritakan Jibril berkata demikian: "belum pernah aku turun membawa kalimat yang lebih agung dari kalimat la ilaha illa Allab, karena dengan kalimat itulah tegaknya langit dan bumi, gunung dan tumbuh-tumbuhan, laut dan daratan. Itulah kalimat ikhlas,

${ }^{8}$ Biasanya kelompok yang suka melontarkan sorotan seperti ini ialah mereka yang termasuk kalangan pembaharu seperti Muhammdaiyah dan Persatuan islam, tetapi terhadap Suryalaya, NU pun sering memcibirnya. Informsi dari Yusuf Hamzah, Wawancara.

${ }_{9}^{9}$ Miftahus Sudur, hlm. 9, pernyataan tersebut didasarkan al-Quran.

10 Ibid., hlm.15 
kalimat Islam, kalimat kedekatan Tuhan, dan kalimat kemenangan. ${ }^{11}$

Abah Anom memandang tarekat yang dikembangkannya sebagai "jalan kepada Tuhan yang harus ditempuh berdasarkan keseimbangan antara aspek syari'at (lahir) dan aspek bakekat (batin). Sebab pola keseimbangan demikian merupakan inti pelaksanaan ajaran Islam yang sebenarnya". ${ }^{12}$ Dikatakan, kesenangan dunia itu tidak harus jadi penghalang seseorang untuk qikrullab. Para murid diperkenankan untuk memenuhi segala kebutuhan duniawi atau keinginan syahwatnya, sepanjang itu dihalalkan agama dan ternyata dapat menguatkan mereka beribadat. Orang boleh berpakaian yang bagus dan makan atau minum yang sedap, agar dia dapat merasakan nikmat Tuhan yang bersifat lahiriah. Begitu pula setiap insan bebas mengembangkan profesinya dalam urusan dunia, tetapi mereka juga hendaknya mengambil tarekat agar hati mereka tidak lupa kepada Tuhan dan bisa terhindar dari perbuatan dosa. ${ }^{13}$
Abah Anom mengharapkan ajaran Tarekat Qadiriyah wa Naqsyabandiyah juga dapat terpantul dalam kebidupan sosial para penganut. Untuk ini Tanbib (wasiat Abah Sepuh kepada semua murid Tarekat Suryalaya) dijadikan sebagai pedoman. Inti ajaran yang dapat dipetik dari dokumen ini agar para murid tidak berbuat yang bertentangan dengan peraturan agama dan negara; mereka harus selalu insaf akan godaan nafsu serta syetan; dan mereka harus selalu menunjukkan kebajikan yang timbul dari kesucian hati seperti saling menghormati, tolong-menolong, ramah-tamah, belas kasihan, dan rukun dengan sesama manusia termasuk kepada orang yang tidak seagama.

\section{Citra Kedamaian melalui Pesantren-Tarekat}

Pengamatan dari banyak sarjana menyimpulkan bahwa syaikh-syaikh tarikat cenderung mendekati penguasa dan mecari pengikut di kalangan elit politik. $\mathrm{Hal}$ ini antara lain ditunjukkan dalam beberapa kasus sejarah dalam hubungan

\footnotetext{
11 lbid., hlm. 21.

${ }^{12} /$ bid., hlm. 47-49.

${ }^{13} / \mathrm{bid}$., hlm. 54.
} 
Syaikh dan Sultan di Nusantara. ${ }^{14}$ Bahkan laporan Belanda abad ke-19 mencatat guru-guru tarekat itu sengaja pada awalnya mendekati kaum bangsawan dan pamongraja, sehingga mendapat restu dari atas, dan baru kemudian menaruh perhatian kepada lapisan masyarakat lainnya. ${ }^{15}$ Kecenderungan seperti ini sudah barang tentu merupakan upaya para syaikh untuk memperoleh perlindungan para penguasa dalam dakwah mereka, tetapi juga mereka berhasil mempengaruhi sikap beragama penguasa yang mereka dekati. Pada gilirannya, para penguasa seringkali mengembangkan hubungan akrab dengan seorang Syaikh tarekat dan bersedia mendengarkan nasehat-nasehatnya. Salah satu alasan penting yang mendorong para penguasa itu, ialah harapan mereka untuk memperoleh karamah (kekuatan spiritual) Syaikh yang dipandang dapat melindugi dan melestarikan kedudukan mereka.

Guru tarekat dijadikan tempat bertanya, misalnya kapan sang penguasa bisa menetapkan sebuah keputusan; apa amalan yang bisa membawa barakah. Untuk memperkokoh legitimasi penguasa di mata pembimbing ruhani, maka penguasa yang sadar bahwa ia telah berbuat banyak dosa kemudian ia mendapat ketenangan hati berkat bimbingannya. ${ }^{16}$ Tampaknya tak dapat diingkari bahwa sikap atau pun harapan seperti itu juga berlaku bagi kalangan lain seperti pengusaha, pedagang, pegawai, buruh, dan petani.

Pada periode awal pengembangan tarekat di Pondok Pesantren Suryalaya, Syaikh Abdul Mubarrok dihadapkan kepada tantangan yang membuatnya tidak leluasa berdakwah, yaitu akibat kecurigaan pihak penguasa $\mathrm{Be}$ landa dan birokrat pribumi serta para ulama yang antipati terhadap tarekat. Dapat diperkirakan bahwa Syaikh pada waktu itu telah memperoleh pengikut dari kalangan petani atau buruh penduduk setempat. Dalam suasana yang masih labil itu, Syaikh juga berusaha meminta bantuan tokoh masyarakat di tingkat Kabupaten, agar Bupati Tasikmalaya mengeluarkan izin atas

${ }^{14} \mathrm{Martin}$ van Bruinessen, "Tarekat dan Politik: Amalan untuk Dunia atau Akhirat", dalam Pesantren, No. 1 Vol. IX, 1992, hlm. 6.

${ }^{15} \mathrm{lbid}$., hlm. 7.

16 Ibid. 
berdirinya pesantren itu. Tokoh dimaksud adalah Soetisna Sendjaja (Soet Sen), seorang pemimpin Paguyuban Pasundan dan belakangan menjadi tokoh NU cabang Tasikmalaya. Selain itu Syaikh melakukan pendekatan kepada pihak penguasa di Bandung, terutama kepada Raden Hasan Moestapa, Penghulu Bandung yang pernah bersama-sama menuntut ilmu tarekat kepada Syaikh Tolkhah di Cirebon. Atas bantuan penghulu ini, Abdullah Mubarrok dipertemukan dengan Bupati Bandung, sehingga ia memperoleh dukungan darinya untuk melangsungkan dakwah Tarekat Qadiriyah wa Naqsyabandiyah. Kedua penguasa tersebut sangat terkenal di masyarakat Priangan sebagai penguasa-penguasa yang menaruh banyak perhatian terhadap masalah keagamaan, termasuk tarekat. ${ }^{17}$ Dukungan mereka itu cukup berarti bagi Ajengan Godebag, dan secara tidak langsung berpengaruh terhadap para penguasa di daerah ini.
Sewaktu Bupati Tasikmalaya masih saja menaruh curiga terhadap kegiatan tarekat di Suryalaya itu, ia menugaskan Wedana Ciawi, Raden Sumantaredja, untuk mengawasi serta menyelidiki kegiatankegiatan tarekat yang ada di wilayahnya. Namun wedana ini selain memandang bahwa gerakannya tidak berbahaya, ia sendiri bahkan menyatakan diri sebagai murid Syaikh Abdul Mubarrok. ${ }^{18}$ Semenjak itu pengaruh Syaikh mulai kuat di kalangan penguasa pribumi, bahkan Bupati TasikmÔlaya, R.A.A Wiratanoeningrat, pernah minta bantuan (karamab)-nya bagi kelangsungan proyek Rawa Lakbok, ${ }^{12}$ dalam usaha pengeringan dan pembibitan ikan siam, yang pada waktu itu termasuk Mooi Bestuunverk di wilayah Priangan Timur. ${ }^{21}$ Permintaan serupa datang dari Bupati Ciamis pada peristiwa pemberontakan Komunis tahun 1926, seterusnya Syaikh diberi kedudukan terhormat menjadi penasehat dan pembimbing keagamaan Bupati.

${ }^{17}$ Sunardjo, Sejarah Pesantren Suryalaya, hlm. 34.

${ }^{18} \mathrm{lbid} ., \mathrm{hlm} .32$.

${ }^{19}$ Rawa ini adalah rawa paling luas di wilayah Priangan Timur. Lakbok kini adalah juga nama Kecamatan, yang sejak tahun 1938 termasuk dalam wilayah Kabupaten Ciamis, Maman Abdul Malik, Dinamika Kaum Santri, hIm 30.

${ }^{20}$ M. Soetardja \& Dr. Ratoelangi, "De Droogelegh", Overdruk unit Pemimpin, The Jaargang, No. 11 Mei 1936. 
Berkat hubungan yang semakin membaik antara Syaikh Abdullah Mubarrok dan para penguasa pribumi itu, masyarakat lainnya dari perkotaan banyak yang terpikat atas ajaran yang dikembangkan Syaikh. Di antara mereka ialah $H$. Sobari pemilik percetakan Galungan dan tuan Hoed pemilik toko emas asal Pakistan di Tasikmalaya; H. Madjid pengusaha jagal sapi di Pasar Ciawi; Raden Kartamihardja yang populer dengan panggilan Juragan Bank dari kota Garut; dan Badjuri seorang pengusaha restauran dari Gedebage Bandung. ${ }^{21}$ Setelah ditalqin, mereka sering datang kepada Syaikh guna mengikuti amalan berjamaah di Suryalaya, dan atas jasa mereka Tarekat Qadiriyah wa Naqsyabandiyah bisa tersebar di kalangan pengusaha ataupun pedagang.

Pada periode 1930-an penganut Tarekat Sury:laya bertambah banyak. Kini bukan saja rakyat umum yang datang dari desa-desa sekitar seperti Puteran, Cikoranji, Cicero, Bojongsoban, Parung, dan Harentang, melainkan juga para ajengan dari desa-desa tersebut yang dulu bernada sinis kepada Ajengan Gode- bag. Sentimen para ajengan itu, menurut K.H. Noor Anom, sesungguhnya karena mereka masih menganggap asing terhadap tasawuf atau tarekat, padahal mereka sendiri tidak sepenuhnya memandang salah terhadap ajaran tarekat. Permasalahan yang sering menjadi sorotan mereka ialah praktek qikir jabar dan membayangkan guru dalam rangka tawajuh. Sentimen merekapun pada awalnya lebih disebabkan oleh sikap adu domba pihak Belanda. ${ }^{22}$ Oleh karena itu dapat diduga bahwa kesediaan para ajengan berguru ke Suryalaya adalah setelah mereka memandang sah dan mengetahui arti pentingnya tarekat. Sikap mereka yang demikian memberi dampak yang sangat menguntungkan bagi penyebaran penganut itu.

Walaupun jumlah penganut Tarekat Suryalaya pada tahun menjelang berakhirnya periode kekuasaan Belanda tidak dapat dipastikan, tetapi berdasarkan catatan Djoehriah Besman, bahwa setiap acara manaqiban pada tahun 1937 tidak kurang dari 500 orang penganut yang datang ke Suryalaya. ${ }^{23}$ Selain mereka yang datang dari desa-desa tersebut,

\footnotetext{
${ }^{21}$ Besman, Sinar Hate, hm. 36-45.

${ }^{22}$ Wawancara dengan K.H. Noor Anom.

${ }^{23}$ Besman, Sinar Hate, hlm. 63.
} 
pada acara ini juga biasa hadir penganut dari Pangandaran, Ciamis, Rajapolah, Indihiang, Ciawi, Pakuwon Garut, dan Bandung. Bahkan telah ada pula yang datang dari daerah Pekalongan, Brebes, Tegal, dan Pemalang Jawa Tengah. ${ }^{24}$ Pada masa itu Syaikh juga sering berkunjung ke daerah-daerah di mana terdapat sejumlah penganutnya dan di sana ia memberikan talqin kepada muridmurid baru.

Pada periode pendudukan Jepang dan awal kemerdekaan, meskipun situasi sosial-politik dan ekonomi di wilayah Priangan sangat memprihatinkan, tamu-tamu yang datang hendak berguru tarekat ataupun tujuan lainnya bertambah banyak. Menurut seorang saksi sejarah, tujuan para tamu itu pada umumnya bukan saja belajar Tarekat Qadiriyah wa Naqsyabandiyah, mereka juga meminta amalan serta keberkahan bagi kekayaan, naik pangkat, dan mengatasi krisis kehidupan keluarga. Disamping itu banyak pula yang bertujuan men- dalami ilmu saepi $i^{25}$, yaitu ilmu untuk memperoleh ketenangan batin serta kekuatan mental agar bisa tawakkal atas segala nasib. Pencarian ilmu tersebut dilakukan dengan cara berkhalawat selama 40 hari dengan mandi tengah malam dan diteruskan amalan wirid. ${ }^{26}$ Model khalwat seperti ini sangat mungkin ditempuh oleh para penganut pada waktu itu, sehubungan dengan kekacauan yang dihadapi oleh mereka akibat Revolusi Kemerdekaan dan kemudian pemberontakan DI/ TII, sehingga mungkin mereka berkhalawat sambil mengungsi.

Semenjak awal periode 1960 -an, yakni dalam situasi keamanan di wilayah Priangan Timur mulai pulih kembali, Abah Anom bertambah leluasa mengembangkan ajaranya. Sejak itu pula ia memperoleh dukungan dari kalangan elit politik, antara lain Haji Sewaka Akbar mantan Gubernur Jawa Barat (19471952) dan mantan Mentri Pertahanan RI (1952-1953), yang talqinnya kepada Abah Anom pada

${ }^{24} /$ bid., hlm. 66.

${ }^{25} / / m u$ Saepi sangat populer di kalangan masyarakat Priangan yang dipahami sebagai ilmu gaib atau ilmu kadigdayaan. Boleh jadi istilah saepi diambil dari kata Arab saepun yang berarti pedang disimbulkan sebagai kekuatan, tetapi mungkin juga berasal dari kata sup, salah satu akar kata dari tasawuf. 1996.

${ }^{26}$ Wawancara dengan bapak Eleh (74), penduduk Suryalaya, pada tanggal 7 Pebruari 
tahun 1961. Berkat dukungan tokoh ini, tuduhan bahwa Pesantren Suryalaya mengembangkan ajaran yang tidak benar mulai menipis di kalangan masyarakt Priangan. ${ }^{27}$ Hingga akhir periode ini, pertumbuhan penganut Tarekat Qadiriyah wa Naqsyabandiyah begitu pesat, sebagaimana menurut pemantauan S. Soebardi dalam penelitianya tahun 1973, bahwa jumlah peserta manaqiban dalam setiap penyelenggaraannya mencapai sekitar 2.000 orang. Menurut penelitian ini, mereka terdiri dari petani, militer, pedagang yang berasal dari Bandung, Bogor , Cianjur, serta beberapa yang berasal dari bagian utara Jawa Tengah, dan masyarakat umum dari penduduk lokal (Tasikmalaya, Garut, dan Ciamis). ${ }^{28}$ Sudah barang tentu jumlah yang sesungguhnya bisa lebih banyak lagi daripada yang hadir dalam upacara tersebut.

Otoritas kepemimpinan Abah Anom yang didasarkan pada kharisma spiritual, membuat dirinya amat disegani oleh berbagai kalangan. Namun ia tidak mengarahkan para pengikutnya untuk bergabung dalam suatu ormas keagamaan tertentu. Dia membebaskan mereka untuk berafiliasi menurut kecenderungannya, apakah mereka ingin aktif di NU, Muhammadiyah, Persatuan Islam, ataupun PUI (Persatuan Ummat Islam). Sekalipun dengan NU, halmana organisasi Tarekat Qadiriyah wa Naqsyabandiyah di Jawa pada umumnya berada dalam naungannya, Abah Anom tidak mau menjadikan tarekatnya sebagai bagian dari ormas itu. Adapun kaitannya dengan organisasi politik, semenjak Orde Baru, Suryalaya memang merupakan gudang suara bagi Golongan Karya, bahkan pasca Pemilu 1982 Abah Anom diangkat menjadi Pinisepuh dalam kepemimpinan Golkar tingkat pusat. ${ }^{24}$ Meskipun begitu ia pun tak pernah melarang pengikutnya untuk tidak memasuki organisasi politik lain, sepanjang organisasi tersebut tidak dilarang oleh Negara dan Pemerintah. Kecenderungan sikap politik seperti ini merupakan perwujudan dari landasan ideologis kalangan Suryalaya, sebagaimana tertuang dalam Tanbib.

\footnotetext{
${ }^{27}$ Unang Sunardjo bahkan menyebutkan bahwa Sewaka pernah mengeluarkan pengumumam secara besar-besaran mengenai dukungannya, melalui surat kabar daerah.

${ }^{28} \mathrm{~S}$. Soebardi, Spectrum, hlm. 228.

${ }^{29}$ Pengangkatannya sebagai Pinisepuh ini berdsarkan Piagam Penghargaan dari Golkar di Jakarta tahun 1984, yang di tandatangani oleh, ketua Dewan Pembina Golkar, Soeharto.
} 


\section{Simpulan}

Berdasarkan gambaran di atas mengenai Pesantren-Tarekat dalam hubungannya dengan kedamaian, dapatlah diambil beberapa simpulan. Pertama, Pesantren dengan pengembangan pendidikannya berbasis Tarekat mencerminkan kekhasan pembinaan agama untuk kedamaian seseorang atau kelompok masyarakat baik dalam hubungan mereka dengan Tuhan maupun pengaruhnya terhadap hubungan sesama manusia. Pembinaan agama secara demikian amat tergantung kepada figur pimpinan pesantren, dalam hal ini Syeikh Tarekat. Kedua, Kepemimpinan Syeikh, berdasarkan contoh kedua figur Ajengan di Suryalaya, mampu dan telah berusaha menciptakan kedamaian personal dan sosial di kalangan para penganutnya, terutama karena faktor akomodatif dan toleransi yang dikembangkannya berhadapan dengan berbagai tantangan zaman serta keragaman sosial-budaya. Ketiga, khususnya berhadapan dengan penguasa (kekuatan politik) yang seringkali menjadi bahan benturan antara realitas keagamaan dan politik, dicontohkan oleh kepemimpinan Syaikh melalui pengembangan potensi kharismatik dan partisipasi aktifnya sebagai mediator antara rakyat dan pejabat. Itulah sebabnya "Pesantren dengan basis Tarekat berpotensi bagi masa depan pembangunan kedamaian di negeri ini". Wallabul Musta'an

\section{SUMBER BACAAN}

Djoehriah Besman, Sinar Hate, Brosur, t.t.

Dudung Abdurahman. Gerakan Tarekat Qadiriyab wa Naqsyabandiyah Suryalaya di Tasikmalaya, 1905-1995. Tesis S2 (telah diterbitkan), Pascasarjana UGM Yogyakarta, 1997.

Hiroko Horikoshi, Kyai dan Perubahan Sosial, terj. Umar Basalim dan Andi Muarly Sunrawa. Jakarta : P3M, Cet. I, 1987.

M. Soetardja \& Dr. Ratoelangi, "De Droogelegh", Overdruk unit Pemimpin, The Jaargang, No. 11 Mei 1936.

Maman Abdul Malik, Dinamika Kaum Santri di Tasikmalaya, 1900-1942. Tesis S2 UGM Yogyakarta, 1992.

Martin van Bruinessen, "Tarekat dan Politik: Amalan untuk Dunia atau Akhirat", dalam Pesantren, No. 1 Vol. IX, 1992.

Shahibul Wafa Tajul 'Arifin, Miftabus Sudur, Pondok Pesantren Suryalaya, t.t.

Uqudul Juman, dan Tanbib.

Unang Sunardjo, Sejarab Pesantren Suryalaya. Tasikmalaya: Pondok Pesantren suryalaya, t.t. 